\title{
EMISSÕES DE COMPOSTOS ORGÂNICOS VOLÁTEIS SELECIONADOS DURANTE O PROCESSO DE SECAGEM DO ALBEDO E DO FLAVEDO DE LARANJA-PÊRA (Citrus Sinensis $L$. Osbeck).
}

\author{
C. L. PINHEIRO ${ }^{1}$, O.P. TARANTO ${ }^{2}$ e E. TOMAZ ${ }^{2}$ \\ ${ }^{1}$ Universidade do Estado do Amazonas - Engenharia Química (EST-UEA) \\ ${ }^{2}$ Universidade Estadual de Campinas - Faculdade de Engenharia Química \\ E-mail para contato: claironlp@yahoo.com.br
}

\begin{abstract}
RESUMO - A operação de secagem para obtenção de farelo de polpa cítrica em indústrias de suco de laranja emite compostos orgânicos voláteis (COVs) para a atmosfera causando problemas relacionados à poluição do ar. Desta forma, estudou-se a emissão de COVs durante a exposição de conjuntos de partículas de albedo e flavedo de laranja-pêra a fluxo de ar seco com velocidade constante em diferentes tempos de exposição e a sete temperaturas. Coletaram-se amostras de gás na saída do fluxo de ar e quantificou-se por cromatografia gasosa com detector de ionização por chama (CGDIC): furfural, $\alpha$-pineno, $\beta$-pineno, 3-careno, $\mathrm{p}$-cimeno e d-limoneno. Os principais compostos emitidos foram o d-limoneno, 3-careno e $\alpha$-pineno a partir do flavedo com tendência ao aumento da emissão com a temperatura e diminuição com o tempo de exposição. Emissão de COVs por arraste a vapor pode ter ocorrido associada à volatilização por efeito do fluxo de ar e da temperatura deste e, além disto, pôde-se notar que a secagem conduzida com fluxo de ar dentro de uma faixa de temperatura pode proporcionar uma secagem eficiente e com moderadas emissões de voláteis.
\end{abstract}

\section{INTRODUÇ̃̃o}

Durante o processamento da laranja, $45 \%$ da produção é de suco e $49 \%$ de bagaço (Yamanaka, 2005), que pode ser definido como cascas (pericarpo), sementes e materiais fibrosos, que são enviados à unidade do processo chamada fábrica de ração. Nesta unidade, o bagaço é submetido à operação de secagem para obtenção de farelo de polpa cítrica. Essas operações de beneficiamento do bagaço e sua comercialização evitam a disposição do mesmo como resíduo em aterros e elimina os custos com disposição (Rodrigues e Viégas, 1980; Braddock, 1995). No entanto, durante a secagem, compostos orgânicos voláteis (COVs) (como d-limoneno, $\alpha$-pinenos e furfural) e compostos odoríferos são emitidos para a atmosfera. Desta forma, a secagem torna-se uma fonte primária de poluição do ar (Gentry et al., 2001) e os COVs emitidos podem causar problemas ambientais, como episódios de desconforto olfativo da população que vive nas proximidades da indústria, assim como favorecer a formação de ozônio troposférico e do smog fotoquímico (Seinfeld e Pandis, 1998).

Dentro deste contexto, o objetivo deste trabalho foi estudar a emissão de COVs selecionados durante a exposição de amostras padronizadas de bagaço (albedo e flavedo) a fluxos de ar a diferentes temperaturas e tempos de exposição a fim de minimizar as emissões e compreender que mecanismos são responsáveis pela liberação dos COVs do bagaço para o fluxo de ar. 


\section{MATERIAIS E MÉTODOS}

Um lote de laranjas-pêra foi adquirido e lavado em água corrente e armazenado a $5^{\circ} \mathrm{C}$. Para os experimentos diários, três laranjas-pêra eram selecionadas e as cascas (pericarpo) cortadas em quatro seções meridionais (Figura 1.a). Discos padronizados de albedo (parte branca da casca) e flavedo (parte verde da casca) com $0,8 \mathrm{~mm}$ de espessura e $12 \mathrm{~mm}$ de diâmetro foram obtidos (Figura 1.b e 1.c) utilizando um cortador circular, uma base metálica com um furo de $12 \mathrm{~mm}$ e um estilete. Os discos obtidos eram armazenados a $5^{\circ} \mathrm{C}$ e utilizados durante o dia de experimentos.

O módulo experimental utilizado para secar os discos de albedo e flavedo é apresentado no esquema da Figura 2 e foi composto por um compressor (1), leito de sílica gel (2), leito de carvão ativado (3), rotâmetro (4), resistores (5), regulador de tensão (6), câmara de vidro borossilicato (7), termopar com visor de temperatura (8), suporte de discos (9), aparato para coleta de gás (10), seringa gastight (11) e bomba para amostragem de gases (12).

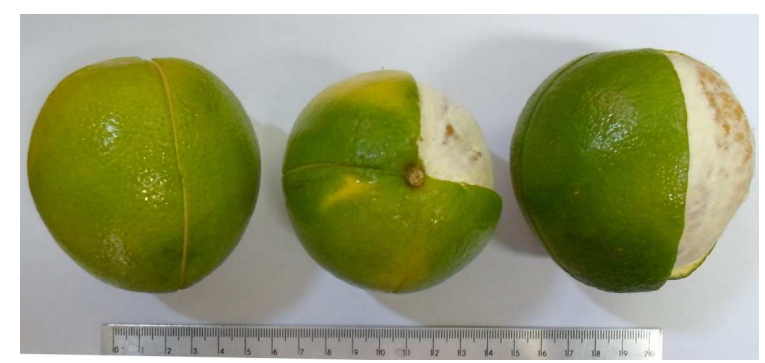

(a)

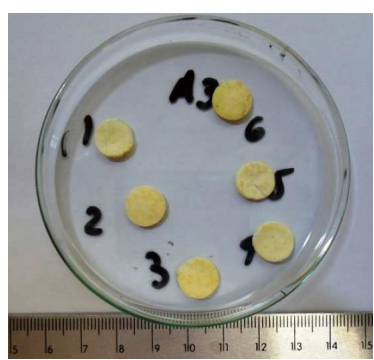

(b)

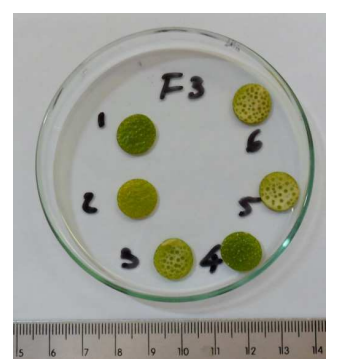

(c)

FIGURA 1 - (a) Laranjas-pêra cortadas em seções meridionais, (b) discos de albedo e (c) discos de flavedo.

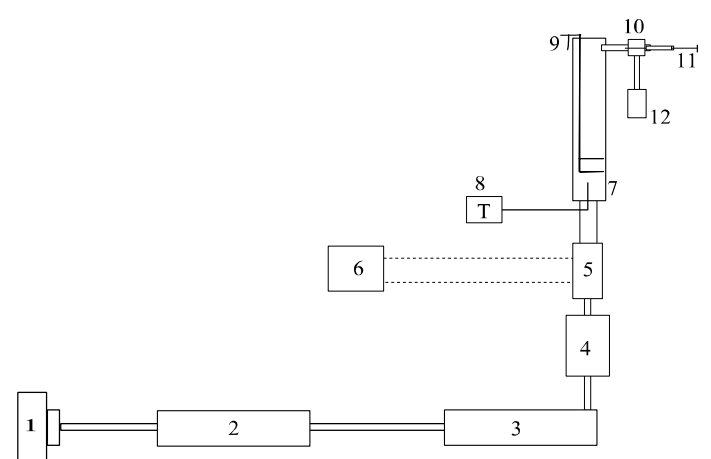

Figura 2 - Módulo experimental de secagem em leito fixo e sistema de coleta de gases.

A vazão do fluxo de ar na câmara de vidro era regulada pelo rotâmetro para manter velocidade constante a $0,5 \mathrm{~m} / \mathrm{s}$. Os discos de flavedo e albedo eram fixados no suporte de discos (uma haste de platina) A quantidade de discos fixados no suporte em cada corrida eram 12 de flavedo e 14 de albedo. A amostra de gás para análises foi coletada com uma bomba de amostragem de gases (Ametek, Alpha-2 air sampler, a $30 \mathrm{~mL} \cdot \mathrm{min}^{-1}$ ) e uma seringa gastight de $100 \mu \mathrm{L}$ (Hamilton). Os compostos-alvo selecionados foram furfural, $\alpha$-pineno, $\beta$-pineno, 3 -careno, e dlimoneno. As quantificações dos COVs coletados nas corridas experimentais foram feitas a partir de curvas analíticas determinadas para cada composto, semelhantes à Equação 1, onde: $A$ é a área do pico correspondente ao COV (mV.s); $a$ é o coeficiente angular (mV.s.ng $\left.{ }^{-1}\right), b$ é o coeficiente linear (mV.s) e; $m_{C O V}$ relacionada à área do pico (ng), obtidas pela injeção de soluções com os padrões analíticos dos COVs selecionados diluídos em metanol. 
A Equação 2 foi utilizada para calcular as taxas de emissões dos COVs, onde: $\dot{m}_{C O V}$ é a taxa de emissão $\left(\mathrm{mg}^{-1}{ }^{-1}\right) ; V_{\text {gás }}$ é o volume de gás amostrado $(100 \mu \mathrm{L}) ; \mathrm{Q}_{\text {Rot }}$ é a vazão apresentada na

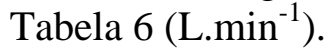

$A=a \cdot m_{\mathrm{COV}}+b$

$\dot{m}_{C O V}=0,6 \cdot \frac{m_{C O V}}{V_{g a ́ s}} \cdot Q_{R o t}$

O método cromatográfico utilizado na obtenção das curvas analíticas e nos ensaios experimentais é apresentado na Tabela 1. Nas análises de CG, as condições de operações do DIC foram: $250^{\circ} \mathrm{C}$, vazão de ar e de hidrogênio a 420 e $45 \mathrm{~mL} \cdot \mathrm{min}^{-1}$, respectivamente. As condições de injeção foram: $230^{\circ} \mathrm{C}$, modo split 1:9. Utilizou-se o cromatógrafo gasoso AutoSystem XL Gas Chromatograph (Perkin Elmer) com injeção direta das amostras, coluna capilar utilizada NST-05 com fase estacionária de metil-fenil polisiloxano entrecruzado e imobilizado com $60 \mathrm{~m} \times 0,25 \mathrm{~mm} \times$ $0,25 \mu \mathrm{m}$ ( $1 \mathrm{x}$ d.i. x e). A fase móvel utilizada foi hélio a 1,0 mL. $\mathrm{min}^{-1}$.

Tabela 1 - Método cromatográfico

\begin{tabular}{cccc}
\hline & TAXA $\left({ }^{\circ} \mathrm{C} \cdot \mathrm{min}^{-1}\right)$ & TEMPERATURA $\left({ }^{\circ} \mathrm{C}\right)$ & TEMPO DE ESPERA (Minutos) \\
\hline Inicial & 0 & 45 & 5 \\
Passo 1 & 2,5 & 70 & 2,5 \\
Passo 2 & 2,0 & 100 & 2,5 \\
\hline
\end{tabular}

As corridas experimentais foram realizadas em três sequências de experimentos. Na primeira sequência de experimentos, as temperaturas do fluxo de ar foram 70,160 e $250^{\circ} \mathrm{C}$. Essas temperaturas foram escolhidas para se ter um conhecimento inicial de como a emissão de COVs ocorria em uma temperatura: inferior a ponto de ebulição da água; na faixa do ponto de ebulição ( 155 e $176^{\circ} \mathrm{C}$ ) dos compostos selecionados; acima do ponto de ebulição do composto menos volátil. O tempo de exposição dos discos ao fluxo de ar quente e a temperatura deste fluxo em variáveis codificadas em "níveis" são apresentados na Tabela 2.

Tabela 2 - Codificação dos níveis de temperatura e de tempo de exposição

\begin{tabular}{ccc}
\hline NÍVEL & TEMPERATURA $\left({ }^{\circ} \mathbf{C}\right)$ & TEMPO \\
\hline-1 & 70 & $\mathrm{t}_{1}$ \\
0 & 160 & $\mathrm{t}_{2}$ \\
1 & 250 & $\mathrm{t}_{3}$ \\
\hline
\end{tabular}

Os valores de $t_{1}, t_{2}$ e $t_{3}$ variaram com a temperatura do fluxo de ar e com o material (albedo ou flavedo). Assim, considerou-se: $\mathrm{t}_{1}$ : período de 2 minutos aplicado a todas as temperaturas e para albedo e flavedo; $t_{2}: 50 \%$ do valor de $t_{3}$ e; $t_{3}: 80 \%$ do período que um disco de material (albedo ou flavedo) levou para apresentar massa constante (observado apenas a $70^{\circ} \mathrm{C}$ ) ou carbonizar-se totalmente (para temperaturas superiores a $70^{\circ} \mathrm{C}$ ). A Tabela 3 apresenta os valores dos tempos de exposição das amostras $\left(\mathrm{t}_{\mathrm{i}}\right)$ os três níveis de temperatura da primeira sequência de experimentos. Nessa sequência foram realizados 36 experimentos.

A segunda sequência de experimentos foi realizada após a análise dos resultados da primeira sequência e apenas as amostras de flavedo foram expostas ao fluxo de ar. As temperaturas do fluxo 
de ar foram intermediárias entre 160 e $250^{\circ} \mathrm{C}$ com intervalos de $15^{\circ} \mathrm{C}$ entre cada uma e são apresentadas na Tabela 4 (em variáveis codificadas). Essas temperaturas foram adotadas para se obter mais informações sobre o comportamento da taxa de emissão dos COVs. Os tempos de exposição $t_{1}, t_{2}$ e $t_{3}$ variaram com a temperatura do fluxo de ar, conforme apresentados na Tabela 5 . Nesta sequência foram realizados 30 experimentos.

Tabela 3 - Tempo de exposição $\left(t_{i}\right)$ das amostras padronizadas de albedo e flavedo ao fluxo de ar para os três níveis de temperatura da primeira sequência de experimentos

\begin{tabular}{ccccccc}
\hline $\mathbf{T}$ & \multicolumn{2}{c}{$\mathbf{t}_{\mathbf{1}}$ (min) } & \multicolumn{2}{c}{$\mathbf{t}_{\mathbf{2}}(\mathbf{m i n})$} & \multicolumn{2}{c}{$\mathbf{t}_{\mathbf{3}}$ (min) } \\
\cline { 2 - 7 }$\left({ }^{\circ} \mathbf{C}\right)$ & Flavedo & Albedo & Flavedo & Albedo & Flavedo & Albedo \\
\hline 70 & 2 & 2 & 20 & 12 & 40 & 24 \\
160 & 2 & 2 & 6 & 6 & 12 & 12 \\
250 & 2 & 2 & 4 & 4 & 8 & 8 \\
\hline
\end{tabular}

Tabela 4 - Codificação dos níveis de temperatura do fluxo de ar para os níveis de temperatura da segunda sequência de experimentos

\begin{tabular}{|l|c|c|c|c|c|}
\hline NÍVEL & $1 / 6$ & $1 / 3$ & $1 / 2$ & $2 / 3$ & $5 / 6$ \\
\hline TEMPERATURA $\left({ }^{\circ} \mathbf{C}\right)$ & 175 & 190 & 205 & 220 & 235 \\
\hline
\end{tabular}

Tabela 5 - Tempo de exposição $\left(\mathrm{t}_{\mathrm{i}}\right)$ das amostras padronizadas de flavedo ao fluxo de ar para os três níveis de temperatura da segunda sequência de experimentos

\begin{tabular}{cccc}
\hline T $\left({ }^{\circ} \mathbf{C}\right)$ & $\mathbf{t}_{\mathbf{1}}$ nível “-1" & $\mathbf{t}_{\mathbf{2}}$ nível “0” & $\mathbf{t}_{\mathbf{3}}$ nível "1" \\
\hline 175 & $2 \mathrm{~min}$ & $6 \mathrm{~min}$ & $12 \mathrm{~min}$ \\
190 & $2 \mathrm{~min}$ & $6 \mathrm{~min}$ & $12 \mathrm{~min}$ \\
205 & $2 \mathrm{~min}$ & $5 \mathrm{~min}$ & $10 \mathrm{~min}$ \\
220 & $2 \mathrm{~min}$ & $4 \mathrm{~min}$ & $8 \mathrm{~min}$ \\
235 & $2 \mathrm{~min}$ & $4 \mathrm{~min}$ & $8 \mathrm{~min}$ \\
\hline
\end{tabular}

As vazões reguladas no rotâmetro para compensar a expansão térmica do fluxo de ar após o aquecimento são apresentadas na Tabela 6.

Tabela 6 - Vazões para compensação de expansão térmica e sequência de experimentos

\begin{tabular}{|c|c|c|c|c|c|c|c|c|c|}
\hline TEMPERATURA $\left({ }^{\circ} \mathbf{C}\right)$ & 70 & 150 & 160 & 175 & 190 & 205 & 220 & 235 & 250 \\
\hline QRot $\left(\mathbf{L} / \mathbf{m i n}^{\circ} \mathbf{2 5}^{\circ} \mathbf{C}\right)$ & 9,91 & 8,00 & 7,85 & 7,59 & 7,34 & 7,11 & 6,89 & 6,69 & 6,50 \\
\hline
\end{tabular}

A terceira sequência de experimentos foi realizada após análise dos resultados das duas sequências anteriores e apenas amostras de flavedo foram expostas ao fluxo de ar para a obtenção do teor de umidade $\left(\mathrm{X}_{\mathrm{A}}(\mathrm{t})\right)$ e de taxa de emissão de $\mathrm{COV}$ em função do tempo de exposição. As temperaturas do fluxo de ar foram 150,205 e $250^{\circ} \mathrm{C}$. Essas temperaturas foram adotadas para analisar a taxa de emissão em uma temperatura: abaixo do ponto de ebulição de todos os compostos-alvo, em uma condição intermediária e na condição mais extrema adotada neste trabalho. Após a exposição do conjunto de amostras de flavedo, dois discos eram coletados e o teor de umidade $\left(\mathrm{X}_{\mathrm{A}}\right)$ era medido por Karl Fischer, obtendo-se um teor de umidade médio na amostra $\left(\mathrm{X}_{\mathrm{A}, \text { médio }}\right)$. Nesta sequência foram realizados 64 experimentos. 


\section{RESULTADOS E DISCUSSÃO}

A Figura 3 apresenta o cromatograma para uma injeção de $0,5 \mu \mathrm{L}$ da solução padrão dos COVs selecionados com concentração de $0,1 \mu \mathrm{L} / \mathrm{mL}$ e serve para ilustrar os cromatogramas para determinação das curvas analíticas, assim como apresenta o tempo de retenção dos compostos.

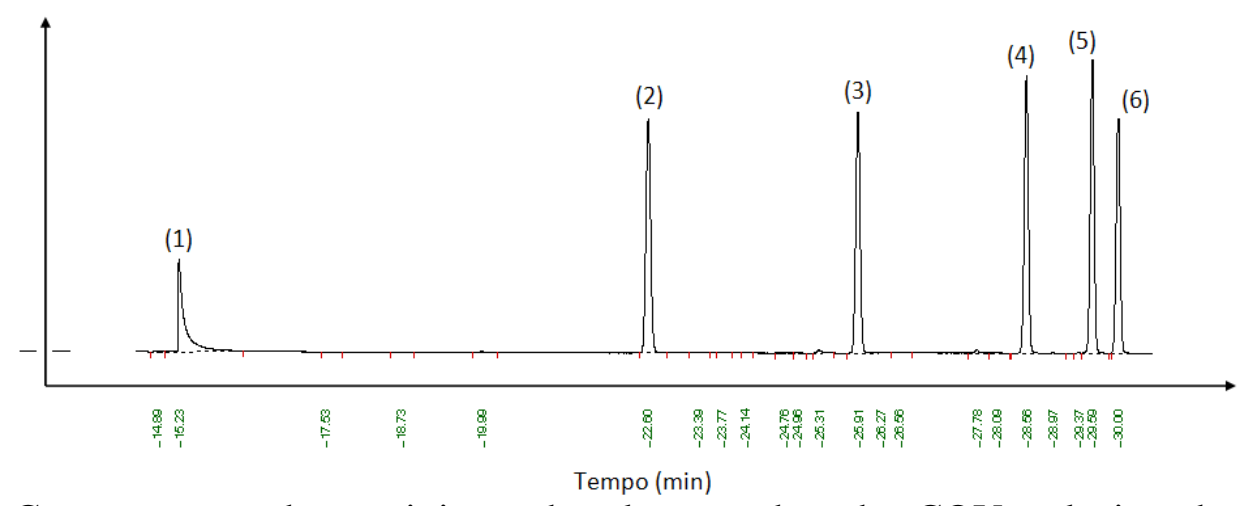

Figura 3 - Cromatograma de uma injeção de solução padrão dos COVs selecionados, sendo (1)

furfural, (2) $\alpha$-pineno, (3) $\beta$-pineno, (4) 3-careno, (5) para-cimeno e (6) d-limoneno.

Os resultados da primeira sequência de experimentos mostraram que os principais compostos emitidos foram: d-limoneno, 3-careno e $\alpha$-pineno. Notou-se um comportamento onde a emissão dos COVs a 70 e $160^{\circ} \mathrm{C}$ diminuía e, a $250^{\circ} \mathrm{C}$, aumentava (Figuras 4.a, 4.b e 4.c), enquanto que a $250^{\circ} \mathrm{C}$ esperava-se um comportamento semelhante àquele notado a 70 e $160^{\circ} \mathrm{C}$. Assim, pôdese inferir que, entre 160 e $250^{\circ} \mathrm{C}$, havia um fenômeno que explicasse o aumento de taxa de emissão com o tempo. Com relação às taxas de emissão a partir do albedo, elas foram da ordem de 10 vezes inferiores às do flavedo (Figura 4.d), justificando que este é a principal fonte de emissão de COVs durante a exposição a fluxo de ar aquecido. Portanto, justificando a não utilização do albedo nas demais sequências de experimentos.

Os resultados da segunda sequência de experimentos mostraram que os principais compostos emitidos foram: d-limoneno, 3-careno e $\alpha$-pineno. Quando flavedo foi exposto ao fluxo de ar, a mudança de comportamento da emissão de $\alpha$-pineno e d-limoneno ocorreu entre 190 e $220^{\circ} \mathrm{C}$, semelhante ao da primeira sequência. Mas, a $205^{\circ} \mathrm{C}$, notou-se um comportamento intermediário, no qual a taxa de emissão diminuiu e, em seguida, aumentou (Figura 5.a). Para o 3careno, a mudança de comportamento foi entre 175 e $220^{\circ} \mathrm{C}$. Porém, o comportamento intermediário foi notado a 190 e $205^{\circ} \mathrm{C}$ (Figura 5b).

As hipóteses levantadas para as mudanças de comportamento da emissão de $\alpha$-pineno e dlimoneno (entre 190 e $220^{\circ} \mathrm{C}$ ) e 3 -careno (entre 175 e $220^{\circ} \mathrm{C}$ ) foram fenômenos relacionados ao arraste por vapor e à temperatura de ebulição destes compostos. Deste modo, a terceira sequência de experimentos foi realizada visando entender e explicar o comportamento de aumento da taxa de emissão com o tempo. A partir dessas hipóteses, os resultados mostraram que os principais compostos emitidos foram d-limoneno, 3-careno e $\alpha$-pineno, sendo que as taxas de emissão de dlimoneno foram 100 a 1000 vezes superiores às de 3 -careno e $\alpha$-pineno. Portanto, este foi o principal composto liberado durante a exposição de flavedo a fluxos de ar a diferentes temperaturas. 


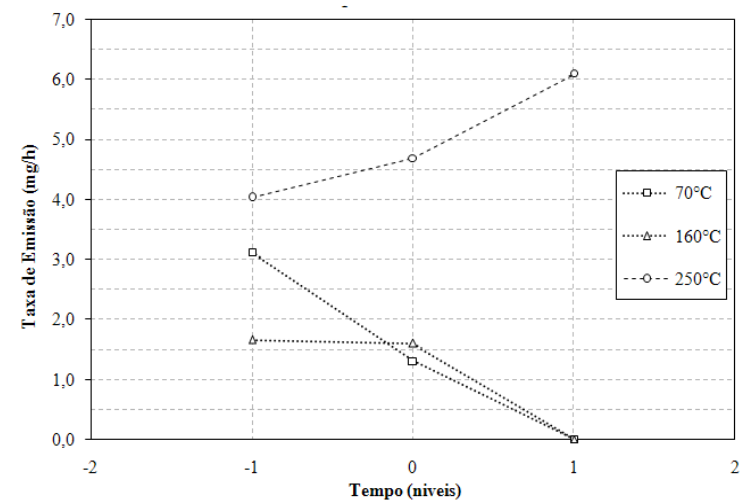

(a)

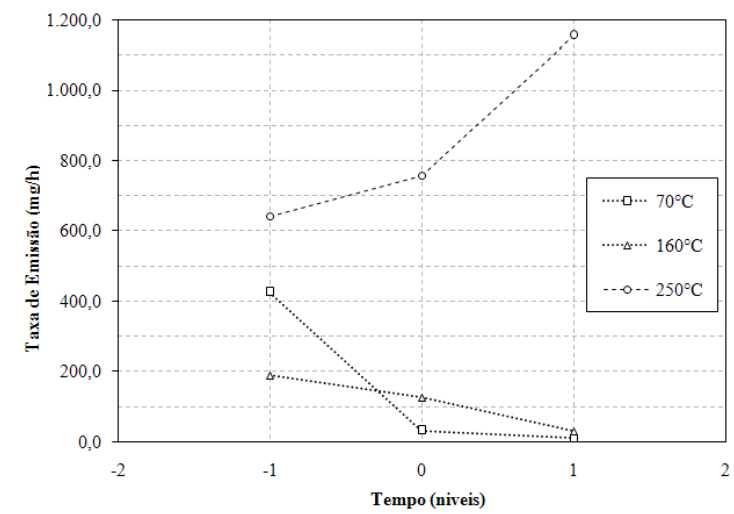

(c)

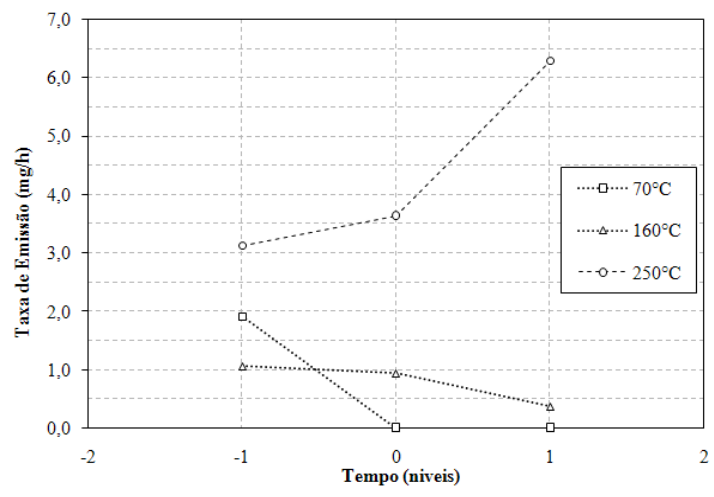

(b)

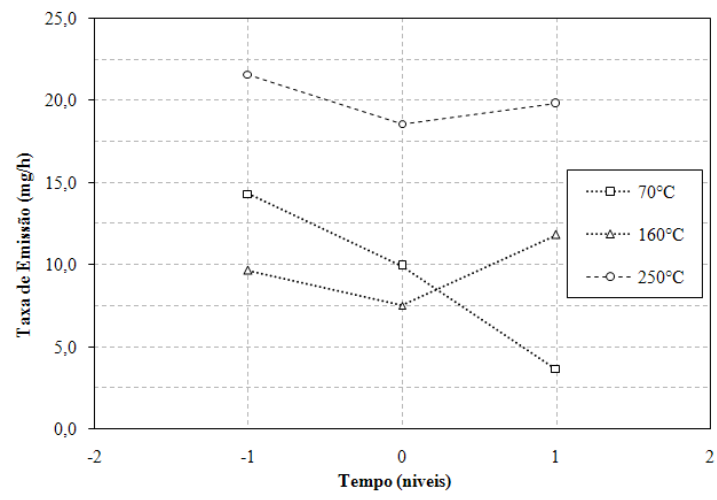

(d)

FIGURA 4 - Taxas de emissão média dos COVS na primeira sequência de experimentos a partir do flavedo para (a) $\alpha$-pineno, (b) 3-careno, (c) d-limoneno e (d) d-limoneno a partir do albedo.

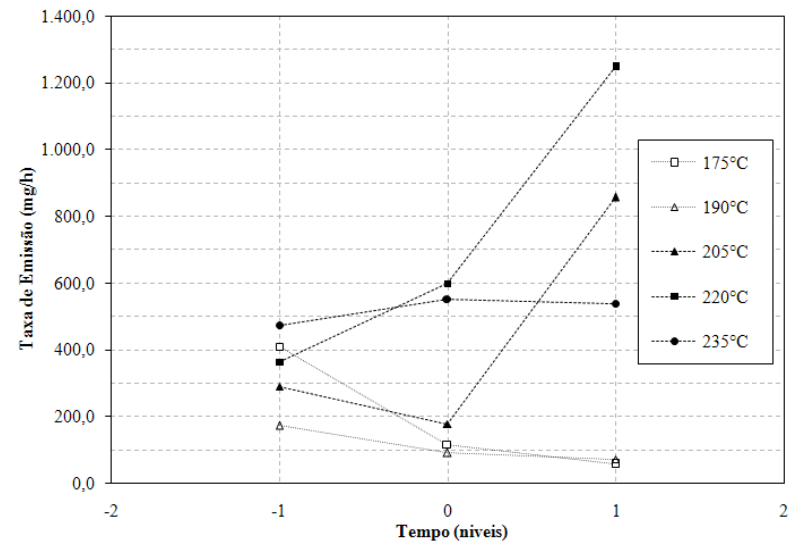

(a)

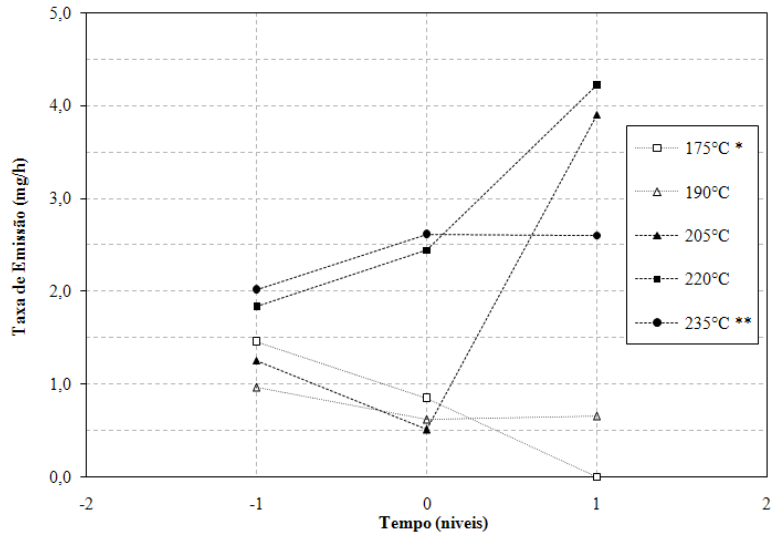

(b)

FIGURA 5 - Taxas de emissão média dos COVS na segunda sequência de experimentos a partir do flavedo para (a) d-limoneno e (b) 3-careno.

Notou-se também que as taxas de emissões dos compostos orgânicos voláteis aumentaram com o aumento da temperatura do fluxo de ar, como é possível verificar na Figura 6. Além disso, foi possível observar uma mudança na forma da curva de taxa de emissão versus tempo com o aumento da temperatura, em que se destaca uma mudança de tendência a partir de 6 minutos de tempo de exposição, especialmente para temperaturas acima de $220^{\circ} \mathrm{C}$. 


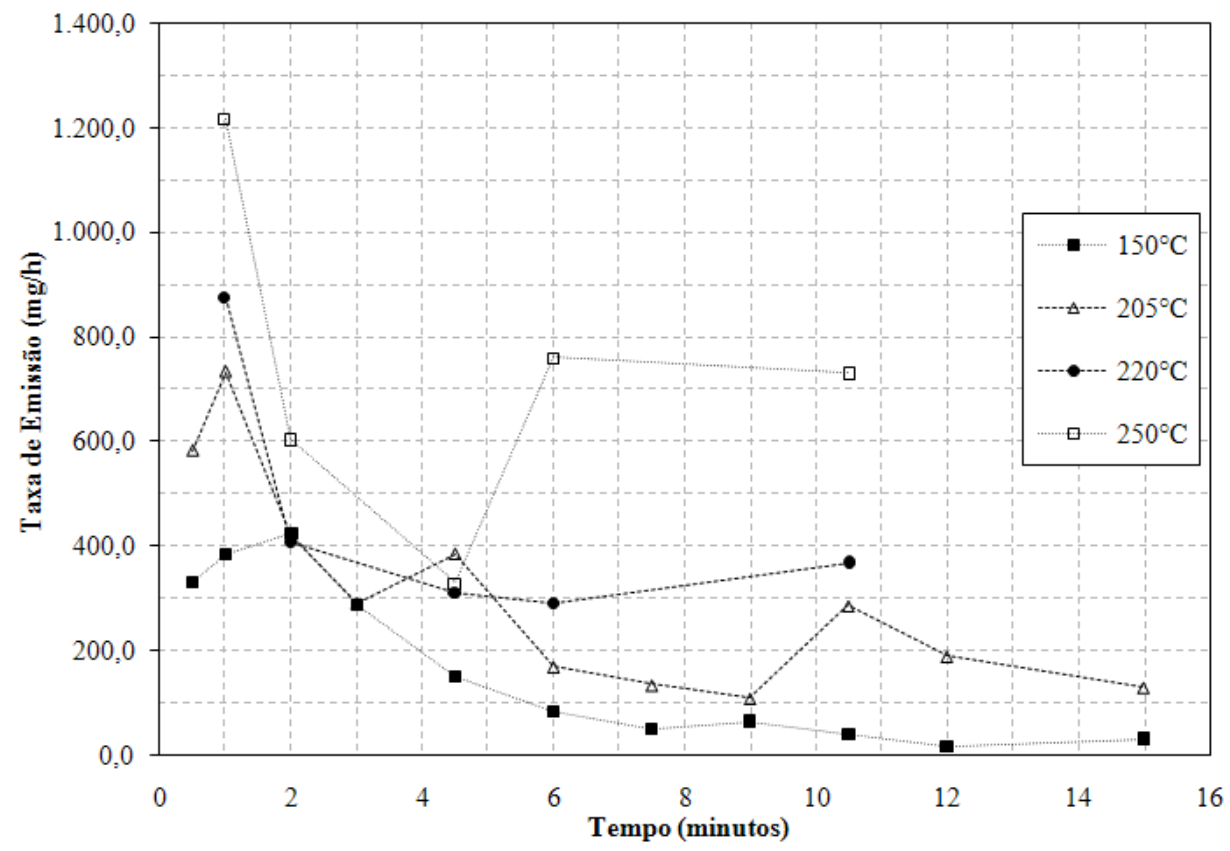

Figura 6 - Taxa de emissão média de d-limoneno na terceira sequência de experimentos.

Para temperatura do fluxo de ar a $150^{\circ} \mathrm{C}$, a taxa de emissão variou de $400 \mathrm{mg} / \mathrm{h}$ até praticamente se anular, acompanhando em termos de tendência a evolução da umidade na amostra (Figura 7.a). Como a temperatura dos gases permaneceu abaixo da temperatura de ebulição dos COVs, apenas uma parte foi transferida para a fase gasosa, com contribuição provável do processo de arraste a vapor. A Figura 7.a mostra como a taxa de emissões de COVs apresentou a mesma tendência da variação de umidade com o tempo de exposição.

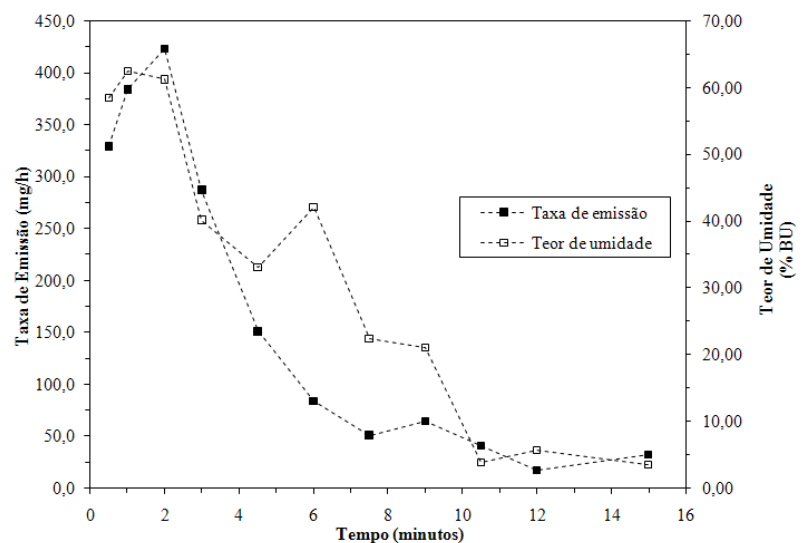

(a)

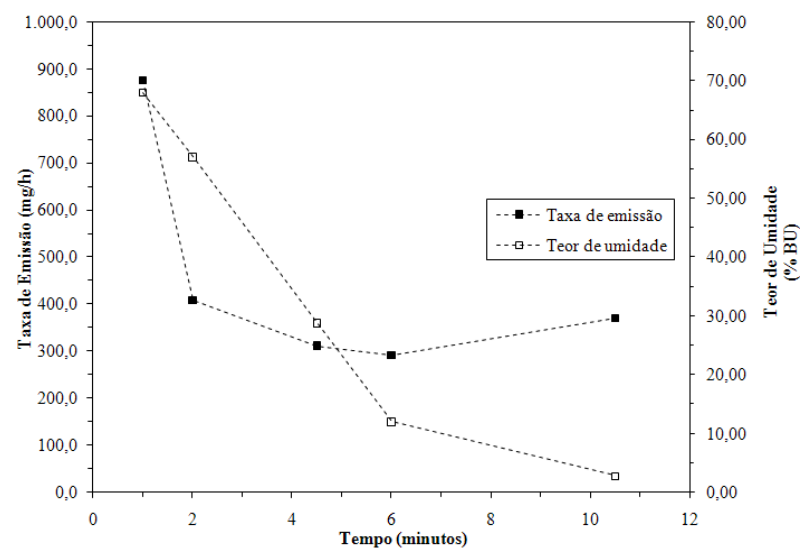

(b)

FIGURA 7 - Comparação entre as variações da taxa de emissão média e do teor de umidade média, ambos em função do tempo de exposição, para o d-limoneno a (a) $150^{\circ} \mathrm{C}$ e (b) $220^{\circ} \mathrm{C}$.

Com os gases a $205^{\circ} \mathrm{C}$, observou-se um comportamento semelhante ao obtido para $150^{\circ} \mathrm{C}$, com taxas de emissões maiores, justificada pela temperatura mais elevada. Nesta condição, parte significativa da amostra tem a sua temperatura limitada pela temperatura de bulbo úmido da água ainda presente. A taxa de emissão de COVs se elevou apenas depois de 10 minutos de tempo de exposição, quando o teor de umidade atingiu um valor baixo suficiente para não limitar a temperatura da amostra. 
Para temperaturas de fluxo de ar a 220 e $250^{\circ} \mathrm{C}$, observou-se uma mudança de tendência a partir de 6 minutos de tempo de exposição, quando a taxa de emissão sofreu um aumento. Analisando-se a Figura 7.b, observou-se que com 6 minutos de tempo de exposição o teor de umidade é em torno de $10 \%$, condição na qual a taxa de emissão começa a aumentar.

\section{CONCLUSÃO}

O estudo dos COVs emitidos de amostras padronizadas de albedo e flavedo de laranja-pêra expostas a fluxo de ar em diferentes temperaturas e tempos de exposição mostraram que os principais compostos emitidos foram o d-limoneno, 3-careno e $\alpha$-pineno e as maiores taxas de emissão foram de d-limoneno e observou-se também que a taxa de emissão dos COVs apresentou uma tendência de aumento com o aumento da temperatura do fluxo de ar para um mesmo tempo de exposição. Além disso, notou-se que a contribuição do albedo na emissão pode ser desprezada.

Outro ponto se refere às fases do processo de secagem de bagaço, onde notou-se duas fases importantes quanto às emissões de COVs. Uma delas é a inicial entre 0 e 2 minutos de tempo de exposição, quando ocorrem altas taxas de emissão e de perda de voláteis. Este período é curto e pode ser amenizado operando-se com temperaturas moderadas. A outra fase é após 6 minutos de tempo de exposição, quando a umidade atinge valores baixos (abaixo de 10\%) e para temperaturas elevadas (acima de $220^{\circ} \mathrm{C}$ ), a taxa de emissão de COVs voláteis assume a tendência de elevação.

Na primeira fase, a temperatura na amostra é limitada pela temperatura de bulbo úmido da água, evitando elevadas taxas de emissão, que provavelmente são incrementadas pelo arraste a vapor de água. Na segunda fase, devido à baixa umidade, a maior parte da amostra não está mais limitada pela temperatura de bulbo úmido da água e a temperatura da amostra deve estar mais próxima da temperatura do fluxo de ar. Para temperaturas acima de $220^{\circ} \mathrm{C}$, as taxas de emissão ficam elevadas e duram mais tempo do que a primeira fase.

Pode-se concluir que a temperatura do fluxo de ar entre 150 e $200^{\circ} \mathrm{C}$ pode proporcionar uma secagem eficiente e com emissões moderadas de COVs, muito menores do que em temperaturas superiores a $220^{\circ} \mathrm{C}$, que devem ser evitadas.

\section{REFERÊNCIAS}

BRADDOCK, R. J. e MILLER, W. M. (1978). Some moisture properties of dried citrus peel, Proc. FL State Hort. Soc. 91: 106 - 109.

GENTRY, T. S. et al. Volatile organic compounds from citrus feed mill emissions. Journal of Food Process Engineering, v. 24. 2001. p. 1-15.

RODRIGUEZ, O e VIÉGAS, F. C. P. Fundação Cargil: Citricultura Brasileira. São Paulo, 1980.

SEINFELD, J. H. e PANDIS, S. N. Atmospheric Chemistry and Physics - From Air Pollution to Climate Change, John Wiley \& Sons, Inc., USA, 1998.

YAMANAKA, H. T. Sucos cítricos. Série P+L, São Paulo: CETESB, 2005. 45p. 